Herz 2015 · 40:1011

DOI 10.1007/s00059-015-4319-y

Received: 9 March 2015

Accepted: 3 April 2015

Published online: 28 July 2015

(c) Urban \& Vogel 2015

CrossMark

\section{Tomislav Miljak}

Department of Interventional Cardiology, Academic Teaching Hospital Sindelfingen, Sindelfingen, Germany

\section{Comment to}

Docic S, Kovacevic D, Bjelobrk M et al (2015)

Spontaneous regression of proximal LAD

subocclusive stenosis after left internal

mammary artery bypass grafting. Herz 40:79-

81. doi: 10.1007/s00059-013-3907-y

\section{To the Editor}

In a recent issue of HERZ, Dodic and colleagues described the phenomenon of complete disappearance of a subocclusive ostial stenosis of the left anterior descending (LAD) artery [1].

This interesting case report raises some questions: Because neither the computed tomographic coronary angiography, performed in 2012, nor the former coronary angiogram, done in 2004, showed significant calcification at the LAD ostium, it would be interesting to know:

a. Whether in 2004 a second angiogram was done after administration of intracoronary nitroglycerine to rule out coronary spasm

b. Whether in 2012 intravenous ultrasound or optical coherence tomography was performed to examine the vascular anatomy in the area of the former stenosis.

Sustained coronary artery spasm-although rare-is known to mimic obstructive coronary artery disease [2] as well as being a potential pitfall for inadvertent coronary artery bypass grafting [3].

Tomislav Miljak, MD, MBA

\section{Corresponding address}

\section{T. Miljak MD, MBA}

Department of Interventional Cardiology

Academic Teaching Hospital Sindelfingen

Sindelfingen

t.miljak@klinikverbund-suedwest.de

\section{Compliance with ethical guidelines}

Conflict of interest. T. Miljak states that there are no conflicts of interest.

\section{References}

1. Docic S, Kovacevic D, Bjelobrk M et al (2015) Spontaneous regression of proximal LAD subocclusive stenosis after left internal mammary artery bypass grafting. Herz 40:79-81. doi: 10.1007/s00059-0133907-y

2. Ahooja $V_{\text {, Thatai }} \mathrm{D}$ (2007) Multivessel coronary vasospasm mimicking triple-vessel obstructive coronary artery disease. J Invasive Cardiol 19:E178E181

3. Mohammed AA, Yang A, Shao K et al (2013) Patients with left main coronary artery vasospasm inadvertently undergoing coronary artery bypass grafting surgery. J Am Coll Cardiol 61:899-900 